\title{
Out of the Pacific: A second fossil porpoise from the Pliocene of the North Sea Basin
}

Wouter Colpaert, Mark Bosselaers, and Olivier Lambert

Acta Palaeontologica Polonica 60 (1), 2015: 1-10 doi:http://dx.doi.org/10.4202/app.00115.2014

Although modern porpoises (Phocoenidae, Odontoceti, Cetacea) occupy most oceanic regions of the world, their fossil record outside the Pacific Ocean remains extremely scarce. Based on a partial skull from lower Pliocene layers (Kattendijk Formation, Zanclean, 5-4.4 Ma) of the Antwerp harbour, a new genus and species of fossil phocoenid, Brabocetus gigaseorum gen. et sp. nov., is described. The new taxon is diagnosed by a unique combination of characters including an anterolateraly widely-open antorbital notch, the anteromedial sulcus being shorter than the posteromedial sulcus, the frontal boss being longer than wide, pronounced asymmetry of the vertex, and the possible presence of an additional longitudinal sulcus across the premaxillary eminence. The phylogenetic analysis indicates that $B$. gigaseorum is not closely related to extant phocoenids; it is included in a clade comprising most north-west Pacific fossil species, two north-east Pacific fossil species, and the only previously described North Sea fossil species Septemtriocetus bosselaersi. Considering the paleobiogeographic distribution of phocoenids, an early Pliocene arrival from the North Pacific to the North Sea may be correlated to the early opening of the Bering Strait and migration via the Arctic. The presence of $S$. bosselaersi in younger deposits (Piacenzian) of the southern margin of the North Sea Basin could be the result of either a second dispersal event, or of local speciation in the North Sea, whereas an additional trans-Arctic migration from the North Pacific lead to the present occupation of the North Atlantic and North Sea by the phylogenetically distantly related harbor porpoise Phocoena phocoena.

Key words: Mammalia, Cetacea, Odontoceti, Phocoenidae, Pliocene, North Sea Basin, Belgium.

Wouter Colpaert [wouterjcolpaert@gmail.com], Research Unit Palaeontology, Universiteit Gent, Krijgslaan 281/S8, 9000 Gent, Belgium; current address: Populiereweg 16, 8680 Koekelare, Belgium. Mark Bosselaers [mark.bosselaers@telenet.be] and Olivier Lambert [olivier.lambert@ naturalsciences.be] (corresponding author), D.O. Terre et Histoire de la Vie, Institut royal des Sciences naturelles de Belgique, rue Vautier 29, 1000 Brussels, Belgium. 
This is an open-access article distributed under the terms of the Creative Commons

Attribution License (for details please see creativecommons.org), which permits unrestricted use, distribution, and reproduction in any medium, provided the original author and source are credited.

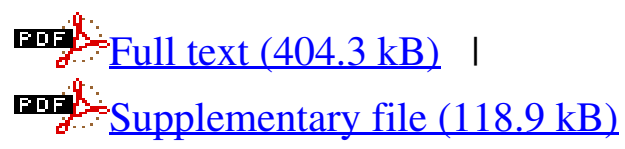

